\title{
Business logistics models in omni-channel: a classification framework and empirical analysis
}

\begin{abstract}
Purpose - Companies are currently moving from multi-channel (MC) strategies to offer their customers an omni-channel (OC) experience. So far, OC research has been mainly tackled from a sales-based view, with numerous operational challenges to be fully investigated yet. The purpose of this paper is to investigate how companies set the logistics variables in their OC management strategy and the business logistics models currently most adopted.

Design/methodology/approach - A two-step methodology was adopted. First, a systematic combining approach with scientific literature review and case studies allowed to derive a framework for classifying the key logistics variables and the related options. The framework was then used to conduct a qualitative survey targeting 92 Italian companies operating in food manufacturing, food retailing and non-food retailing. Collected data were analysed by means of cluster analysis.

Findings - Implementing an OC management strategy requires to set eleven logistics variables belonging to four strategic areas: delivery service, distribution setting, fulfilment strategy, returns management. A broad empirical investigation showed the choices made by companies when setting the logistics variables to implement an OC management strategy. Lastly, four business logistics models, differing in terms of both business sector and OC maturity, were discussed.

Originality/value - The proposed framework extends earlier studies by including additional significant logistics variables. The empirical analysis provides new insights on how to re-structure the business logistics model in OC, suggesting channel integration and the coexistence of multiple configurations as main enablers of an OC proposition.
\end{abstract}

Keywords: Omni-channel, Logistics, Business logistics model, Exploratory study

Paper type: Research paper 


\section{Introduction}

E-commerce sales have grown significantly over the last two decades in all the main markets. This development has progressively induced traditional companies to adopt multi-channel (MC) strategies and include online sales into their businesses. Originally, a MC strategy involved taking the decision as to whether new channels should be added to the existing channel mix (Verhoef et al., 2015) and, from an operational viewpoint, companies preferred to keep traditional and online channels apart (Gallino and Moreno, 2014). The individual channels operated in parallel and were uncoordinated (Beck and Rygl, 2015).

We are now moving towards a new phase, where technology blurs the distinctions between physical and online retailing and using diverse channels as a part of the customer's purchasing process is the rule rather than the exception (Brynjolfsson et al., 2013). The recently coined term omni-channel (OC) indicates that, from the customer's perspective, there is no longer a distinction between traditional and online channels (Beck and Rygl, 2015; Verhoef et al., 2015). Differently from a MC context, an OC strategy considers the integration of business processes and the synergetic management of multiple channels (Verhoef et al., 2015). Existing studies show that an appropriate integration of multiple channels leads to a competitive advantage and channel synergies - such as sales growth, revenue increase - rather than channel cannibalisation (Cao and Li, 2015; Herhausen et al., 2015).

The achievement of this objective is not straightforward. The challenge faced by companies in implementing an OC management strategy is to figure out how to integrate and coordinate operations of traditional and online channels in order to offer a seamless customer's experience regardless of the channel (Bell et al., 2014). As such, a certain company may have reached a certain 'OC maturity' so far, that means a certain ability to integrate and coordinate operations among channels and, thus, a certain ability to provide customers a seamless shopping experience - as shown by several industry reports such as Omni-channel Capability Index by IBM (2015) and Global Omni-channel Retail Index by PwC (2015).

From an operations perspective, new cost-efficient business logistics models must be developed to support such transitional process (Bell et al., 2014), where the key aspect is the integration of different channels. In channel integration, investments are required and issues such as product availability, returns, delivery options and inventory management across the channels need to be addressed (Piotrowicz and Cuthbertson, 2014). Channel integration can occur in a variety of distribution and IT system configurations (Gallino and Moreno, 2014). Companies may use their existing resources (e.g. facilities, personnel) for serving both traditional and online channels or else decide on resources dedicated to the new channel, possibly with a shared information management. Additionally, such 
type of decisions requires addressing several operational problems, such as capacity management (Xie et al., 2014; Hübner et al., 2015), and can be differentiated by product type or customer's segment (e.g. Laseter et al., 2006). We can also expect different business logistics models supporting companies at different stages in their implementation process of an OC management strategy.

In recent years, the research community has expressed increasing interest in designing business logistics models in MC, and OC promises to be an exciting research stream for the near future (Hübner et al., 2016c). Most existing studies on MC are modelling-based contributions, i.e. based on simulation or analytical models (Alptekinoğlu and Tang, 2005; Bretthauer et al., 2010), while conceptual or empirical studies have rarely been proposed (De Koster, 2003; Lang and Bressolles, 2013). Furthermore, such contributions often concentrate on specific logistics sub-problems, such as picking location, inventory integration, delivery mode (Bendoly et al., 2007; Bhatnagar and Syam, 2014), with limited attempts to integrate the different sides of the subject (Hübner et al., 2016b; Hübner et al., 2016c). Additionally, the empirical evidence provided so far relates to a very small number of countries, without offering quantitative analyses, and presents just an early discussion on the development process of an OC management strategy (France in Lang and Bressolles, 2013; Germany in Hübner et al., 2016c).

Given such an evolving landscape towards OC and the current state-of-the-art, the aim of the present paper is two-fold: (i) to provide a broad empirical investigation of the choices made by companies when setting the logistics variables, and (ii) to identify the business logistics models currently adopted by companies, highlighting the main enablers of an OC proposition. To achieve these objectives, a framework for classifying and describing the key logistics variables is defined. We extended the framework proposed by Hübner et al. (2016b), performing a comprehensive review of the existing literature and three case studies, representative of Italian market. Such framework was used as a starting point for the empirical investigation based on a sample of 92 Italian-based leading companies selling products both online and through traditional channels.

The remainder of the paper is organised as follows. The next section provides a summary of the significant literature in this field. Then, the research questions and methodology are described, and the research framework is illustrated. In the final sections, the results are discussed and conclusions are drawn, identifying the research limitations and proposing the directions for future research.

\section{Literature review}

Main logistics issues in multi-channel

The existing research stream on MC retailing mostly focuses on the specific logistics variables that company managers must handle when operating in such a context. For instance, when implementing 
a business logistics model in a MC environment, a first strategic area is the distribution network design. A key variable is the number and types of logistics facilities that companies selling products online and through traditional channels use to handle online orders (Alptekinoğlu and Tang, 2005; Bendoly et al., 2007; Bretthauer et al., 2010). For a company, the decision of whether to use stores or distribution centres (DCs) that also serve the traditional channel or dedicated distribution centres is related to online market size (De Koster, 2003; Bendoly et al., 2007), correlation between online and traditional demand (Alptekinoğlu and Tang, 2005) and transport costs (Liu et al., 2010). As an example, Bretthauer et al. (2010) developed a model to identify the optimal number of logistics facilities that the company needs to fulfil online orders while minimising logistics costs.

Another strategic area for companies operating in a $\mathrm{MC}$ environment consists in inventory management. For instance, the benefits of pooling online and traditional channel inventories have been covered in many studies (Chiang and Monahan, 2005; Schneider and Klabjan, 2013), as well as product availability issues (Bendoly et al., 2005; Fernie and Grant, 2008). More recently, some authors have addressed the problem of allocating online orders, proposing dynamic allocation policies as an alternative to traditional static allocation (Mahar and Write, 2009; Mahar et al., 2009).

Another strategic area that emerged is delivery service. One of the main challenges in e-commerce is typically the 'last mile', i.e. home delivery (HD) (Punakivi et al., 2001). HD can be 'attended', when the consumer is there to receive delivery, and 'unattended', when the customer is not required to be present for the delivery (Kämäräinen and Punakivi, 2002). Although unattended delivery increases flexibility, it can only take place when goods can be left safely, for example in the customer's letterbox (Agatz et al., 2008), and customers are willing to accept this type of delivery. Examining attended HD, many studies focus on time slot management (Punakivi and Saranen, 2001; Agatz et al., 2011) and some authors have recently addressed the problem of differentiated time slot pricing (Klein et al., 2017). Many contributions have also analysed the option - as an alternative to HD - for customers to collect goods bought online from a specific location, such as a locker or shop (Mahar et al., 2012; Wang et al., 2014).

Lastly, several contributions relate to returns management. The online channel is defined by its high returns rate (Bernon et al., 2016). Suitable reverse logistics operations are needed for collecting, checking, repackaging and redistributing the returned goods (Fernie and Sparks, 2014). Looking at the collection process, returned goods can be managed through dedicated facilities or traditional stores (Fernie and Sparks, 2014; Widodo et al., 2011). 


\section{Business logistics models in omni-channel}

In the extant literature, only few papers adopted a comprehensive perspective in addressing the key strategic areas and variables involved when implementing a business logistics model in companies selling products both online and through traditional channels.

We found two literature reviews that gave an overview of the significant logistics variables required in this case and provide a summary of the studies in literature. Swaminathan and Tayur (2003) described five strategic areas that have increased in importance with the emergence of e-commerce (procurement and supplier selection, visibility and information sharing, distribution and pricing, customisation and postponement and decision technology). They argued that companies need to adapt their supply chains to the e-commerce environment, with investments along the supply chain to exploit the benefits of the new channel, and they highlighted the growing need for models to evaluate the impact of changing one or more elements in the supply chain (e.g. inventory, lead time, capacity). Agatz et al. (2008) illustrated the main logistics variables relating to e-fulfilment in MC, structured into two strategic areas (sales and delivery planning and supply chain management). They argued that MC business logistics models can be used to serve different customer's segments, creating synergies and exploiting economies of scale, and they recognised that the interplay between online and traditional channels with regards to logistics is a broad area of research opportunities. Although these reviews represent the first effort to summarise the main logistics variables involved in setting up a MC business logistics model and do offer some insights into the interaction between multiple channels, the focus is on modelling-based papers, which generally do not consider the integration between online and traditional channels in an OC perspective.

Similarly, some authors have proposed comprehensive frameworks involving the key logistics variables for MC companies, using empirical analyses to examine their interdependencies. Lang and Bressolles (2013) identified four e-fulfilment models in MC retailing, looking at the facility in charge of the order (DC or store) and the delivery mode (HD or in-store pickup). They discussed these models and their performance with eight French retailers. Hübner et al. (2015) identified four main strategic areas in MC retail (network design, warehouse operations, inventory management and capacity management) and explored the interdependences among them, identifying and discussing the different options for each strategic area.

More recently, with the advent of the new OC approach, some authors have proposed research frameworks focused on how multiple channels can be synergistically managed to provide a seamless shopping experience. In this line, Hübner et al. (2016a) described the forward and the backward distribution systems in OC retailing, considering the sources (supplier DCs, retailer DCs, stores) and the destinations (home, store). They illustrated advantages and disadvantages of the various design 
solutions and presented the challenges for integrating online and traditional channels. Hübner et al. (2016b) developed a framework for last mile order fulfilment and delivery in OC food retailing, based on explorative interviews with retailers and experts in the grocery industry. According to this framework, logistics variables (picking location, picking automation, picking integration, delivery mode, delivery time, delivery area and returns) are organised around two strategic areas, back-end fulfilment and last mile distribution. They identified different design parameters for each area and discussed how design choices vary according to retailer specifics (e.g. current market position), country features (e.g. population density) and customer behaviour (e.g. willingness to pay for HD). So far, the academic literature has mainly focused on both describing the different options for channel integration and assessing pros and cons of individual options. In the last few years, some attempts were made to study the development process of an OC management strategy. In this line, Hübner et al. (2016c) highlighted the concept of OC maturity, by investigating the transition from MC to OC retailing through an exploratory survey that involved over 60 German retailers and experts. They empirically showed that retailers evolve from using separate inventory systems to channel-integrated inventories, with one common picking zone. This solution also means that inventory allocation should be flexible and demand-driven. Concerning the forward and backward distribution, Hübner et al. (2016c) argued that retailers introduce in-store pick-up and return option besides the postal service. At last, the integration at both organisation and IT systems levels is an enabler for an OC management strategy. Saghiri et al. (2017) developed a conceptual framework for formalising the meaning of integration in OC based on three dimensions: channel stage, channel type and channel agent. They identified integration and visibility as the main enablers of OC management strategies and their implementations, where, from an operational perspective, integration refers to synchronised processes and decisions among different channels. Lastly, some attempts to analyse the OC strategy adopted by companies operating in different countries and sector segments are provided by several industry reports (e.g. PwC, 2015). In particular, the Omni-channel Capability Index by IBM (2015) aims at measuring the OC maturity in different business sectors by comparing the retailers' OC capabilities also from an operational perspective (capability of offering the same day delivery, online information on product availability in store, in-store pick-up and return).

\section{Research questions}

The literature review has revealed a number of logistics variables involved in implementing a business logistics model in OC that relate to different strategic areas (e.g. distribution network design, inventory management, delivery service, returns management). With reference to the OC environment, the most significant contributions seem to be those by Hübner et al. (2016b) and Hübner 
et al. (2016c), who analysed the issue empirically and tried to integrate the different sides of the subject. However, these studies do not provide a comprehensive overview of the logistics issues involved in OC. For instance, transport is not considered as a key issue when defining the business logistics model, although it is a major area for synergy in implementing an OC approach. Furthermore, empirical studies have rarely been proposed on how companies set the logistics variables in implementing their OC management strategy. The few contributions available in literature focus on retailing without comparing various business sectors. Owing to an evolving business landscape in transition from MC to OC, a number of additional key elements need to be considered to help companies define their business logistics model.

Based on this premise, the following research questions (RQs) were identified:

RQ1: How do companies implementing an OC management strategy set the logistics variables?

RQ2: What are the business logistics models (as a combination of the logistics variables) currently used by companies implementing an OC management strategy?

As suggested by previous literature (PwC, 2015; Hübner et al., 2016c), different business sectors are typically characterised by different OC maturity. Thus, to capture the variety of business models we decided to analyse companies operating in three different business sectors, i.e. food manufacturing, food retailing and non-food retailing. Specifically, we selected non-food retailing as, according to the last report provided by the Observatory for eCommerce b2C of Politecnico di Milano, it was the first business sector to be faced by e-commerce sales in Italy, and food retailing that is currently at unrest, with the most important yearly growth rate in 2017 (i.e. 43\%). Then the analysis was extended to manufacturers, specifically food manufacturers, since more and more companies are adding the online channel to their traditional business aiming at providing an OC experience, and very few contributions have been provided so far on this topic in the existing literature (Xie et al., 2014).

\section{Research methodology}

As suggested by similar studies available in literature (Marchet et al., 2017), a two-phase methodology was adopted, as illustrated in Figure 1. In the first phase, we defined the research framework to address our research questions, whereas in phase two we provided empirical insights on business logistics models adopted by companies in implementing their OC management strategy. XXXXXXXXXXXXXXXXXXXXXXXXXXXXXXXXXXXXXXXXXXXXXXXXXXXXXXX

Take in Figure 1

\section{XXXXXXXXXXXXXXXXXXXXXXXXXXXXXXXXXXXXXXXXXXXXXXXXXXXXXXX}




\section{Phase 1: framework development}

To develop the research framework, a 'systematic combining approach' was applied. Systematic combining is a process whereby theoretical framework, empirical fieldwork and case analysis evolve simultaneously, and it is particularly useful in the refinement of existing theories (Dubois and Gadde, 2002). The process started by reviewing the literature on the topic to identify the main logistics variables that companies developing an OC strategy set, as well as their corresponding options. This step produced an initial framework describing the logistics variables that companies take into account when operating in an OC environment based on the available literature. Three case studies were then conducted to adjust the framework by including the industrial viewpoint. The sample selection was based on a theoretical sampling to collect information supporting the development of the framework. Specifically, the cases targeted companies that pioneered the Italian e-commerce market and whose current e-commerce market share in Italy is over $40 \%$ in their respective sector. Moreover, we looked for companies belonging to business sectors characterised by different OC maturity (food manufacturing, food and non-food retailing), with a broad visibility on OC projects worldwide and that have performed detailed analysis when setting their business logistics models. The respondents were Supply Chain or Logistics directors in order to have a broad and strategic perspective on the efulfilment operations. The questions were submitted to the interviews in advance and then phone interviews were arranged in the length of one to two hours. The focused interview format in which the interviewer follows a set of predetermined questions was used. Even so, the interviews remained fairly open-ended to allow the interviewees to express their opinions and experience into certain issues. In addition, secondary data were collected from company website, company reports and published information to provide background and context for the primary research data gathered from the interviews. The interviews were transcribed, integrated with secondary materials and jointly discussed by four researchers. The key outcomes of this process were as follows. On the one hand, the cases confirmed the logistics variables that had emerged from the literature and, on the other, they helped identify several additional significant elements that had not been included previously and/or allowed us to slightly modify some existing ones. Furthermore, the cases allow to accumulate contextual knowledge to facilitate the second phase in terms of both data collection and analysis. The initial framework was successively modified following the empirical findings and the theoretical insights gained during the process.

\section{Phase 2: empirical analysis}

In phase two, an exploratory qualitative survey was conducted. A qualitative survey is a method for defining and investigating variation in populations. It is used to determine the diversity among some 
topics of interest within a given population and establish the meaningful variations within that population, without inferring any statistical representation (Fink, 2003; Jansen, 2010). The unit of analysis was the single company operating in Italy in an OC environment, capturing the business logistics model adopted by each. Our sample consisted of 92 Italian companies, i.e. 57 food manufacturers, 13 food retailers and 22 non-food retailers. We selected these companies starting from the AIDA-Bureau Van Dijk database, considering a company annual revenue threshold over 50 million $€$ for food manufacturers and over 100 million $€$ for food and non-food retailers and, then, filtered the dataset to consider only those companies with e-commerce operations. Tables 1 and 2 present an overview of the selected sample in terms of company turnover and company size expressed as number of employees, respectively.

XXXXXXXXXXXXXXXXXXXXXXXXXXXXXXXXXXXXXXXXXXXXXXXXXXXXXXX

Take in Table 1

XXXXXXXXXXXXXXXXXXXXXXXXXXXXXXXXXXXXXXXXXXXXXXXXXXXXXXX XXXXXXXXXXXXXXXXXXXXXXXXXXXXXXXXXXXXXXXXXXXXXXXXXXXXXXX

Take in Table 2

\section{XXXXXXXXXXXXXXXXXXXXXXXXXXXXXXXXXXXXXXXXXXXXXXXXXXXXXXX}

Following Marchet et al. (2017), semi-structured interviews were employed to explore the answers deemed as most interesting, collect insights and examples and ensure a rounded understanding of the data. The 92 selected companies were contacted by e-mail to ask whether they could be interviewed, with a cover letter explaining the purpose of the research. Interviewees were identified from a database supplied by the Observatory Contract Logistics of Politecnico di Milano that contains contact information of about 600 Supply Chain or Logistics directors and about 150 logistics service providers (LSPs) operating in different sectors. Based on the companies' availability, the interviewees were senior managers working either for the company itself (57 interviews) or for its LSP (9 interviews). LSPs were asked to fill different questionnaire forms, one for each of their customers. Two different versions of the questionnaire were developed around the interviewee type (company manager or LSP), each with three main sections. Section 1 gathered general information about the company (e.g. annual revenue, \% e-commerce turnover/overall company turnover). Section 2 contained questions about its traditional channel logistics (e.g. number of levels in the network, number of stores) and section 3 investigated the company business logistics model for its online channel (options adopted for each identified logistics variable). The interviews lasted around an hour 
and were meant so that cross-case comparisons were possible. Secondary data were also collected from company website, company reports and published information.

Collected data were first analysed through simple descriptive statistics, discussing how companies set the logistics variables (RQ1). Second, the business logistics models (RQ2) were identified by means of a cluster analysis performed in Minitab 17. The logistics variables illustrated in the research framework were considered as input/predictor factors, each forming a nominal attribute with two or more categories. Note that for each variable with multiple responses allowed we introduced the category 'multiple options', used for companies adopting more than one option (e.g. companies using both HD and click and collect $-\mathrm{C} \& \mathrm{C}$ - as delivery mode). Clusters were formed based on differences and similarities between observations and the Ward's method was used. Specifically, considering the type of attributes (i.e. nominal attributes) the similarity between a pair of observations was defined introducing the distance measured as $(n-f) / n$, where $n$ denotes the total number of attributes and $f$ denotes the number of attributes for which the two observations have the same nominal value. Subsequently, a profile of the clusters was developed by introducing the business sector factor. The Pearson Chi-Squared test was used to check statistically significant difference among the company groups regarding the business sector factor.

\section{Research framework}

This section illustrates the resulting framework to describe and classify the logistics variables that companies operating in an OC environment set. As previously stated, this framework was built starting from the earlier study by Hübner et al. (2016b) and was revised and expanded through a comprehensive review of the existing literature and three case studies. The framework is structured according to the four main areas that refer to company strategic decisions: delivery service, distribution setting, fulfilment strategy, returns management. Once the front-end process (marketing strategy regarding price policy and assortment for the online channel) has been defined, the company structures a coherent offer in terms of servicing the online channel and forward distribution system, followed by defining the backward distribution system for goods returned. Each strategic area includes different logistics variables representing the design parameters to be implemented, with multiple options available for each variable.

Figure 2 reports the resulting framework. The individual logistics variables and corresponding options are described below, whereas Table 3 summarises the contribution of literature and case study analysis to the framework. 
Take in Figure 2

XXXXXXXXXXXXXXXXXXXXXXXXXXXXXXXXXXXXXXXXXXXXXXXXXXXXXXX

XXXXXXXXXXXXXXXXXXXXXXXXXXXXXXXXXXXXXXXXXXXXXXXXXXXXXXX

Take in Table 3

XXXXXXXXXXXXXXXXXXXXXXXXXXXXXXXXXXXXXXXXXXXXXXXXXXXXXXX

\section{Delivery service}

Companies operating in an $\mathrm{OC}$ environment need to consider four main logistics variables relating to the delivery service: delivery mode, velocity, time slot and slot price differentiation.

The delivery mode is a key logistics variable for the online channel, as it is the final part of the order process. According to the extant literature (Lang and Bressolles, 2013; Hübner et al., 2016c), companies can decide between two main options: HD and C\&C. In turn, the former can be attended $H D$ or unattended $H D$, while the latter is when customers collect their goods at a given pick-up point, which can be a retailer store (in-store $C \& C$ ), a drive-through centre near a retailer store (attached $C \& C$ ), a locker or locations such as a post office (solitary $C \& C$ ). From the customers' perspective, the delivery mode is mainly a matter of their preference and access to available pick-up points (Nilsson et al., 2015). From the company perspective, the delivery mode affects logistics (for HD, goods are transported by courier; for in-store $\mathrm{C} \& \mathrm{C}$, they may travel with the goods delivered to stores).

Delivery velocity is one of the most highly visible service elements and heavily depends on the industry (product type and customer's requirements). In line with previous contributions (Hübner et al. 2016b), the options can be same day, next day and two or more days. A short lead time to fulfil and deliver an order implies, for instance, to set the picking location very close to the customer.

Aligned to the extant literature (Hübner et al. 2016b), the time slot can be specific or undefined. The former means that customers can choose a time slot during the purchasing process, while the latter includes both HD with no pre-selected time slot and HD on appointment.

Differently from the existing frameworks, the policy of changing price dynamically as a function of the time slot selected by customers is set here as a logistics variable. By pricing time slots differently, companies can balance their use of time slot capacity better, making the delivery process more efficient (Klein et al., 2017). As emerged from the case studies in phase 1, slot price differentiation is apparently being progressively introduced by companies in different European countries and 
business sectors: "Our current van saturation should be improved, and we are working on developing our software to set the pricing based on the time slot capacity” (Case B).

\section{Distribution setting}

In an $\mathrm{OC}$ environment, the distribution setting involves three basic logistics variables: picking location, delivery area and transport service.

Looking at the picking location - where online orders are fulfilled - the options can be central warehouse (CW), separate fulfilment centre and in-store (De Koster, 2003; Alptekinoğlu and Tang, 2005). The second option implies no integration between online and traditional channels, and involves managing replenishment from the $\mathrm{CW}$ to the e-fulfilment centre: "We opened a new warehouse devoted to the online orders fulfilment near Milan; it is replenished three times per week by the Italian central distribution centre" (Case B).

Another key variable is the online order delivery area for each logistics facility. In line with previous contributions (Hübner et al. 2016b), this can be local (5 to 20-kilometre action radius), regional, national and international.

Lastly, differently from the other frameworks available in literature, we considered transport service as an additional logistics variable. The case studies suggested that the transport service is a key element that affects costs. The options can be milk run, Less than Truck Load (LTL) express courier, LTL courier and Full Truck Load (FTL) with local distribution. In the milk run, a vehicle covers closed-loop routes to deliver online orders. In LTL, small parcels are delivered, typically by couriers. In FTL with local distribution, a full lorry transports goods from the fulfilment centre to one node of the network (store or local depot), which, in turn, is the starting point for local distribution routes. FTL transport can be planned by integrating online and traditional flows into an OC perspective: "We ship store and online orders on the same truck, thus reducing the transport cost for the $C \& C$ delivery mode" (Case C).

\section{Fulfilment strategy}

The classification framework highlights three key logistics variables relating to automation, integration and order allocation.

In line with Hübner et al. (2016b), automation can be manual, semi-automated or fully automated. In manual solutions, pickers prepare online orders in traditional picker-to-parts systems. As for Case A, in semi-automated systems, conveyors connect different picking zones although picking is carried out manually (pick-and-pass systems), while parts-to-picker systems are used in fully-automated systems (Marchet et al., 2013). 
As suggested by Hübner et al. (2016b), online order picking can be separated, integrated and, in the next step, capacity-optimised and integrated. This means that the company can use dedicated resources (space and staff) to fulfil online orders or share existing resources to integrate online orders with the traditional channel picking process. As an example, Case $\mathrm{C}$ declared: "We started using the store staff to fulfil online orders, but then we introduced two different teams working separately for traditional and online channels when the online sales increased". The last option (capacity-optimised and integrated) indicates the optimal use of resources to reduce stock-outs and lead times.

In contrast with previous frameworks, we introduced order allocation as a further significant logistics variable. Order allocation can be static or dynamic (Mahar and Write, 2009; Mahar et al., 2012). While static allocation implies defining the picking location for the online order a priori (with only the goods in that location visible to online customers), for dynamic allocation, customers can see the entire range of goods and the responsibilities concerning fulfilling online orders are defined dynamically. As Case C experienced: "In our opinion, the customer should have the visibility on the overall stock available in the network, and then we have to select the best way to deliver the required products in an OC perspective”.

\section{Returns management}

The logistics variable considered for returns management is returns mode. In line with previous contributions (Hübner et al., 2016b), the options are no returns, returns by Courier, Express and Parcel delivery $(C E P)$ and in-store returns. When companies apply a no returns policy, they offer a money-back guarantee. As an alternative, companies can manage returned goods by CEP or give their customers an exchange or refund in a traditional store. According to both Case B and C, the in-store option allows the flow of returned goods either to be integrated with the backward system of the traditional channel, or to be sold again (through the traditional or the online channel).

\section{Results and discussion}

This section illustrates the results of the qualitative survey. First, it presents the options currently in place among the examined companies, as per RQ1. This sub-section has been structured into strategic areas (delivery service, distribution setting, fulfilment strategy, returns management) and the company choices are discussed based on their business sector and OC maturity. It then presents the cluster analysis results, showing the business logistics models currently adopted and highlighting the main enablers of an OC proposition, as per RQ2. 


\section{Descriptive statistical analysis}

Delivery service. Table 4 presents a summary of the options adopted by the examined companies when setting up their delivery service.

\section{XXXXXXXXXXXXXXXXXXXXXXXXXXXXXXXXXXXXXXXXXXXXXXXXXXXXXXX}

Take in Table 4

\section{XXXXXXXXXXXXXXXXXXXXXXXXXXXXXXXXXXXXXXXXXXXXXXXXXXXXXXX}

Looking at the delivery mode, differences do exist among the business sectors. All food manufacturers adopt attended $\mathrm{HD}$, as they typically have no chain of traditional stores. Some companies let customers collect goods at a given pick-up point $(\mathrm{C} \& \mathrm{C})$. In common with Amazon, $5 \%$ of the companies opt for solitary C\&C in post offices. As stated by the logistics director of one manufacturer: "By working with Poste Italiane, since 2014, we have been offering the over 12,000 post offices as pickup points for our customers". Recently, there has also been a rise in 'temporary stores' and 'flagship stores' - shops strategically located to take consumers by surprise and enhance the brand or increase the profit (Kozinets et al., 2002; Surchi, 2011). Only 4\% of the food manufacturers use these stores as online order collection points. In food retailing, $C \& C$ is the dominant delivery mode. Around $31 \%$ of the companies use in-store $\mathrm{C} \& \mathrm{C}$ because they have unused space. As also demonstrated by Gallino and Moreno (2014), this allows the retailer to increase instore traffic, with the ensuing cross-sell and up-sell opportunities. Attached C\&C is used by $38 \%$ of the food retailers, to limit the online flows interfering with the traditional operational processes. Finally, a large number of companies (54\%) also adopt HD, proposing different delivery modes according to the geographical area served. For instance, one company stated: "In cities, customers prefer to receive goods at home, while in the suburbs, customers are quite happy to drive to the store and collect their purchases". Similarly to Lang and Bressolles (2013), in non-food retailing we found that most of the examined companies propose at least two delivery modes, attended HD and in-store $\mathrm{C} \& \mathrm{C}$, so that online customers can select the option that fits their needs best.

With regard to velocity, fast delivery is considered a must for food retailers. Customers expect the process to be extremely fast as their online orders cover their immediate needs. Therefore, $77 \%$ of the food retailers propose same-day delivery. One company revealed that: "New services like Prime Now by Amazon have put pressure on traditional food retailers to reduce their delivery lead time". The situation changes in food manufacturing and non-food retailing, where customers plan their orders and the dominant option is two or more days (in $91 \%$ of the companies). Velocity is important, but same-day or next-day deliveries are neither key elements of differentiation nor cost-effective. 
This is aligned with the results shown by Hübner et al. (2016c) for non-food retailers. Some food manufactures and non-food retailers do offer fast delivery options, charging customers extra.

Looking at time slots, food retailers specify time slots, whereas food manufacturers and non-food retailers prefer open time deliveries. Based on our survey, this result is closely related to the speed of processing the online orders offered to customers. With faster processing, the delivery time slot tends to be defined. Otherwise, specifying a time slot during the purchase is not, apparently, a key element for customers. In non-food retailing, the delivery is typically by appointment when value-added operations are required (e.g. installing appliances). Various food retailers highlighted a trend in their time slot width, typically set between two and four hours, to increase the level of service provided to customers unhappy about having to wait at home for their goods to arrive. As one company indicated: "We have reached a two hours' compromise, given our in-store picking and packing capacity, the lead time with our current transport fleet and the service-cost trade-off. Reducing the time slot any further would mean improving store response capacity and higher fleet flexibility, not always achievable”. In line with previous literature (Agatz et al., 2011), these results highlight the importance of the time slot management problem in attended HD in terms of both customer service and transport cost.

Lastly, companies in our sample do not apply slot price differentiation, as is the case, for instance, in the United Kingdom or Netherlands (Hübner et al., 2016b). The delivery price is seen to be a fixed charge up to now. As stated by the logistics director of a non-food retailer: "Price differentiation would require more advanced IT systems and higher coordination with the marketing department, since commercial issues (order quantity and product type) are also involved".

Overall, comparing our results with other contributions available in literature, we can conclude that the key issue in terms of delivery service is not about finding the most cost-effective solution, but about finding a way to successfully combine the different options available and, thus, provide a valuable $\mathrm{OC}$ experience to the customer.

Distribution setting. The different options adopted in distribution are summarised in Table 5.

XXXXXXXXXXXXXXXXXXXXXXXXXXXXXXXXXXXXXXXXXXXXXXXXXXXXXXX

Take in Table 5

\section{XXXXXXXXXXXXXXXXXXXXXXXXXXXXXXXXXXXXXXXXXXXXXXXXXXXXXXX}

With regards to the picking location, companies can decide among three options, with a different level of integration between online channel and traditional stores. In food manufacturing, the 
dominant option is the separate fulfilment centre (adopted in $65 \%$ of the companies). Typically, CWs supplying traditional stores are unable to fulfil online orders without changing their operations. This is due to the peculiarities of the online orders where piece picking rather than case picking is needed, with additional packaging required. On this point, a manufacturer highlighted that: "The warehouse outbound flows are $66 \%$ full pallet and $34 \%$ cases; traditional orders contain an average of 6 pieces per line. It follows that single piece picking could be very inefficient". The remaining $35 \%$ of food manufacturers prefer to use their own $\mathrm{CW}$. This option seems suitable when the online assortment is limited and the $\mathrm{CW}$ has unused capacity. For instance, a company operating in the beverage industry manages 60 SKUs reserved for their online channel within their $\mathrm{CW}$, retaining an aisle in the traditional picking system for piece picking. In food retailing, an interesting result was that none of the interviewed companies adopts the $\mathrm{CW}$ option. The logistics director of one company explained this choice: "Since the minimum order for traditional stores is one case and the number of SKUs carried at our CW is very high (over 10,000), as is the number of cases shipped per year (on average 45 million), piece picking could lower performance in our warehouse operations". The preferred solution, adopted by $85 \%$ of the analysed companies, is to manage picking in-store. Indeed, as suggested by Hübner et al. (2016b), fast deliveries require setting the picking location very close to the customer. Additionally, given the high volume of their online sales, some retailers prefer to use a separate fulfilment centre close to large urban areas (23\%). According to Ishfaq et al. (2016), having personnel and space capacity not completely used is necessary to integrate online orders in traditional store processes. When the number of online orders increases, the efficiency of an integrated solution decreases so that the introduction of a separate fulfilment centre is probably the most suitable solution (De Koster, 2003; Bendoly et al., 2007). One company provided this example: "We now use separate warehouses for delivering in urban areas, except in one city where we have just introduced our online channel and have decided to process online orders in-store". In non-food retailing, there is greater disparity among company decisions about picking locations. In line with Lang and Bressolles (2013), we found that some retailers use different distribution configurations in parallel. There is probably an optimal configuration for each combination of customer and product, as previously suggested by Laseter et al. (2006). In most of the analysed companies, the picking location changes according to the delivery mode selected by the customer. Online orders involving HD are processed in the CW $(73 \%)$ or separate fulfilment centre $(27 \%)$, while many retailers use in-store picking for C\&C orders. In this way, the retailer does not have to manage frequent small dispatches from the warehouse to the store based on the online demand, but online orders are immediately available at the store to be collected by customers (Hübner et al., 2016a). Picking is also carried out in-store when the CW does not carry the complete assortment. For instance, this is the procedure in a furniture company: "Stores 
carry the complete assortment as only goods imported from Far East are kept in stock at the central warehouse, so local suppliers deliver directly to stores". In the CW, picking areas can be reserved for the online channel or shared between online and traditional channels. For instance, a retailer in the do-it-yourself industry handles the picking operations for 900 fast moving products in ad hoc picking areas, while, for over 40,000 SKUs (those that online customers ask for less) the picking areas are shared with the traditional channel. These results confirm the relationship - already suggested by De Koster (2003) and Bendoly et al. (2007) - between the value of online sales and the picking location selected, as well as they highlight the importance of the current network (number of levels, depots location) and the store features (size, location, assortment) as decision drivers.

With regards to the delivery area, we decided not to include 'international' as option, because the survey results showed that the peculiarities of international deliveries (e.g. cross-border issues) lead to substantial differences within the logistics process itself, so that this option cannot easily be compared with the others. In general, the option decided upon by the company is strongly connected to the speed offered to online customers for processing their order, as previously shown by De Koster (2003), and the distribution network configuration (number and types of picking locations used for the online orders). Having to rely on only one CW in Italy, $98 \%$ of the food manufacturers use a national delivery area, proposing delivery in two or more days. In food retailing, where velocity is a key element and more picking locations are introduced to serve the online demand, the delivery area is local (at most the urban area). In non-food retailing, there are different delivery areas that depend on a company picking location. When this is the store, delivery is organised for local areas, while, when online orders are served from a CW, the delivery area is nation-wide.

Looking at the transport service, there are still differences among the companies operating in the three business sectors. The most suitable option seems to be strongly related to product characteristics, as well as customer's requirements, in line with Laseter et al. (2006). In food manufacturing, the dominant option is LTL, with traditional or express couriers. The first option is possible when velocity is not great (two or more days). Moreover, as asserted by one logistics director: "Traditional couriers can handle temperature-controlled transport much better than express couriers". We also identified a manufacturer that can optimise its transport service through synergy with its traditional channel. As stated by the logistics director: "Our company combines transport, when replenishing traditional stores, we also take goods to local depots, which are then the starting point for HD". The situation changes in food retailing, where all the companies proposing HD use milk runs, which start at the online order fulfilment centre or stores. Among the food retailers, we found interesting examples of synergies with the traditional channel. Some retailers combine online and traditional HD to increase the number of orders per drop and obtain economies of scale, as stated by a company moving in this 
direction: "Initially, we organised our HD service only for our in-store customers who were unable to take their groceries home by themselves. Now, we are integrating traditional and online orders in order to optimise our local distribution routes". In non-food retailing, the dominant option is LTL, with express couriers (36\% of the examined companies) or traditional couriers (55\%). Companies often select multiple options, with a strong segmentation based on product size. As highlighted by a logistics director: "For small items, the most cost-effective option is LTL with express couriers, since they offer more attractive charges (between 4 and 8 euros per delivery, depending on the geographic area and the number of deliveries); with larger items, express couriers are no longer cost-effective and we go for traditional couriers". Furthermore, some retailers use the FTL and local distribution option (18\%). For instance, a company operating in the furniture industry has implemented the following solution: "We have a store where we fulfil our online orders for each regional delivery area and, to save in transport costs, all our goods travel in FTL, combining traditional and online channel flows, and then we organise our local distribution routes starting from these points". While the existing literature is mainly concentrated on optimisation routing problems, our findings show that also the identification of a proper mix of solutions to be adopted is a critical issue for those companies further ahead with the development of an OC management strategy. This entails the need for defining and optimising the integration level in terms of resources (vehicle capacity, drivers).

Fulfilment strategy. Table 6 illustrates the options adopted in the fulfilment strategy.

\section{XXXXXXXXXXXXXXXXXXXXXXXXXXXXXXXXXXXXXXXXXXXXXXXXXXXXXXX}

Take in Table 6

\section{XXXXXXXXXXXXXXXXXXXXXXXXXXXXXXXXXXXXXXXXXXXXXXXXXXXXXXX}

With regards to automation, Italian companies tend to adopt traditional manual solutions, regardless of the business sector. Looking at the food manufacturers, only one company adopts a semiautomated solution. In this case, the number of SKUs is not particularly high (around 400 SKUs), the customers' orders are small (one or a few boxes per order) and are often delivered in kits. As stated by the logistics director of this company: "In this setting, 'pick-and-pass' systems are the best option". With reference to food retailing, the reasons why companies do not adopt automated systems were summarised well by a logistics director: "The difficulty of introducing automated solutions to existing stores and the low volume of online sales do not justify investments in automation". Lastly, in nonfood retailing, a company has automated the picking process for both online and traditional channels, having introduced a shuttle-based storage system (Tappia et al., 2017). 
Regarding the integration between picking for online and traditional channels, there is a higher level of integration in retailing than in manufacturing, with $65 \%$ of the food manufacturers using separate structures and resources for the different channels. This is a result of using a separate fulfilment centre as dominant picking location. Conversely, when the picking location is the $\mathrm{CW}$, picking to fulfil online orders is typically concentrated into a specific time slot during the day and carried out by the same staff working in the traditional channel (35\%). Separate time slots for online and traditional picking harmonize processes, optimising personnel and machines use (Hübner et al., 2015). Most food retailers included in the analysis opt for integrated resources between online and traditional channels (62\%). When the store is the picking location, integration is easily achieved, as the same resources (space and staff) are generally used to manage both traditional sales and online orders. There are, however, some exceptions. For instance, the logistics director of a retailer stated that: "It is better to use different staff for different channels to avoid conflicts". In another company, "Using external workers to fulfil online orders results in quicker response times, as the traditional channel is the priority for store employees". In non-food retailing, $77 \%$ of the companies use an integrated solution, and $41 \%$ a separate solution, so, clearly, some use more than one option: "Most online orders require $H D$ and are fulfilled by the $C W$, while picking takes place in-store for $C \& C$; in the former case, we use dedicated personnel, while, in the latter, we use the traditional channel people as they have surplus time". This integration seems to refer only to the picking process, while packaging, with its specific requirements, always involves dedicated staff.

As regards order allocation, $100 \%$ of the examined food manufacturers and food retailers adopt the static option. For food manufacturers, this is the only choice, as online orders are fulfilled from a single picking location (CW or separate fulfilment centre), while, in food retailing, this is because instore picking is easy to manage. Some retailers are, however, evaluating whether to introduce a dynamic allocation policy to reduce the risk of stock-outs and sales losses. Looking at non-food retailers, $41 \%$ of the companies use a static allocation for online orders, while the remaining $59 \%$ employ dynamic allocation. In a system with multiple picking locations and channel-integrated inventories, orders allocation can be flexible and demand-driven (Hübner et al., 2016c); the company can use the closest location to deliver the order to the online customer (Agatz et al., 2008). Interestingly, the retailers that prefer dynamic allocation have been operating in an OC environment for many years. According to the data gathered, the basic prerequisite to adopt dynamic allocation is to update ones' management system. Companies confirmed that, firstly, they must introduce a virtual warehouse, with real-time visibility of logistics assets, such as inventories and vehicles within the entire network. The virtual warehouse relies on real-time information and real-time decision algorithms to provide operating efficiency and information visibility (Landers et al., 2000). 
Returns management. Table 7 summarises the adoption level of the different options involved in returns management. Returning goods by CEP service is the dominant option for the food manufacturers that have no chain of traditional stores and prefer not to involve temporary and flagship stores (here 100\%). In food retailing, as previously suggested by Hübner et al. (2016b), less than 1\% of online orders are returned, so it is a trivial issue compared to other industries and companies opt for no returns. Lastly, in non-food retailing, companies often offer both CEP (91\%) and in-store (50\%) returns modes. In line with Hübner et al. (2016c), we observe that there are still many retailers not adopting the in-store return option, even if this is a key component of an OC strategy.

XXXXXXXXXXXXXXXXXXXXXXXXXXXXXXXXXXXXXXXXXXXXXXXXXXXXXXX

Take in Table 7

\section{XXXXXXXXXXXXXXXXXXXXXXXXXXXXXXXXXXXXXXXXXXXXXXXXXXXXXXX}

\section{Cluster analysis}

Four clusters (i.e. main business logistics models) were obtained, and then analysed considering the company business sector. The results presented in Table 8 highlight statistically significant difference (Pearson Chi-Squared test) among the company groups regarding the business sector factor. Cluster 1 and Cluster 2 are composed by food manufacturers, whereas food and non-food retailers form Cluster 3 and Cluster 4, respectively.

\section{XXXXXXXXXXXXXXXXXXXXXXXXXXXXXXXXXXXXXXXXXXXXXXXXXXXXXXX}

Take in Table 8

\section{XXXXXXXXXXXXXXXXXXXXXXXXXXXXXXXXXXXXXXXXXXXXXXXXXXXXXXX}

Summarising, the cluster analysis reveals company groups that are clearly different from one another regarding both logistics variables and business sector, highlighting also different OC maturity. According to the profiles obtained, clusters can be named: (1) Separated model; (2) Integrated warehousing model; (3) Store-based model; (4) Multiple-configuration model. These four distinct business logistics models are described below.

Separated model (Figure 3). In food manufacturing, delivery is an important element, but not yet a major source of differentiation. Companies are keen to offer HD (87.5\%), with a velocity of two or more days (77.5\%). The time slot is undefined (97.5\%) and there is no differentiated time slot pricing $(100 \%)$. Looking at the distribution setting, this first group of food manufacturers introduces a 
separate fulfilment centre $(100.0 \%)$. This choice combines the efficiency of traditional warehouse operations with economies of scale and specific expertise developed in this area by the LSP. Since a single depot typically serves the entire country, the delivery area is national (97.5\%). To minimise distribution costs, transport service is typically managed by LTL courier (82.5\%). Looking at their fulfilment strategy, companies are not investing in automation, tending to use manual picking procedures $(97.5 \%)$. Adopting separate logistics facilities to handle online orders means that there is no integration between online and traditional orders during picking operations (100.0\%), and, since a single depot typically serves all the country, the allocation is static (100.0\%). Given the lack of collection points, returned goods are generally managed by CEP delivery (97.5\%).

\section{XXXXXXXXXXXXXXXXXXXXXXXXXXXXXXXXXXXXXXXXXXXXXXXXXXXXXXX}

Take in Figure 3

\section{XXXXXXXXXXXXXXXXXXXXXXXXXXXXXXXXXXXXXXXXXXXXXXXXXXXXXXX}

Integrated warehousing model (Figure 4). This model is adopted by food manufacturers that are looking for integration at a warehousing level, with search for synergies between online and traditional channels in both inventory management and picking activities ( 20 food manufacturers out of a total of 57 included in the sample). The picking location is the CW (100.0\%), the picking to fulfil online orders is normally concentrated into a specific time slot during the day and carried out by the same staff working in the traditional channel (100.0\%). This model seems suitable when the online assortment is limited, the $\mathrm{CW}$ has unused capacity and its operations are already organised per pieces.

\section{XXXXXXXXXXXXXXXXXXXXXXXXXXXXXXXXXXXXXXXXXXXXXXXXXXXXXXX}

Take in Figure 4

\section{XXXXXXXXXXXXXXXXXXXXXXXXXXXXXXXXXXXXXXXXXXXXXXXXXXXXXXX}

Store-based model (Figure 5). In food retailing, companies are actively seeking for synergy between online and traditional channels during picking and transport processes. Looking at their delivery mode, food retailers offer $\mathrm{C} \& \mathrm{C}(76.9 \%)$, with pickup in-store or drive-through centres near the retailer store, as the only option $(46.1 \%)$ or an alternative to HD $(30.8 \%)$. In food retailing, customers expect their purchasing process to be fast. Companies consequently offer same day delivery $(69.2 \%)$ with specific time slots $(100.0 \%)$. As a compromise between service and cost, the time slot width currently in use by Italian companies varies between two and four hours, although there is no slot price differentiation as yet (100.0\%). In an OC perspective, food retailers use stores to fulfil online 
orders (76.9\%). This means that the benefits of integrating online and traditional flows are perceived as higher than the potential associated inefficiencies. In addition, since food retailers adopt the store as their picking location, the delivery area is local (100.0\%) and the dominant transport service is the milk run $(53.8 \%)$. Picking is manual, as automation cannot be introduced in the store $(100.0 \%)$. Online orders are well-integrated into the traditional picking process (61.5\%) and, in some cases, integration also includes the distribution process (online orders and orders placed in-store with HD are dispatched with the same vehicle). Order allocation is still static (100.0\%), even if some retailers are considering whether to introduce dynamic order allocation to reduce the risk of stock-out and lost sales. Food retailers experience a very low returns rate, managing exceptions (e.g. damaged products) through a money-back guarantee $(100.0 \%)$.

\section{XXXXXXXXXXXXXXXXXXXXXXXXXXXXXXXXXXXXXXXXXXXXXXXXXXXXXXX}

Take in Figure 5

\section{XXXXXXXXXXXXXXXXXXXXXXXXXXXXXXXXXXXXXXXXXXXXXXXXXXXXXXX}

Multiple-configuration model (Figure 6). Non-food retailers tend to consider it more important to offer multiple delivery mode options than providing very fast delivery services. Customers can choose between HD and C\&C (55.5\%), as well as multiple delivery lead times (66.7\%). The time slot is not defined when the order is placed (100\%), but often the delivery is by appointment and so far the price does not vary whatever the time slot selected (100.0\%). In non-food retailing, multiple configurations are introduced to be able to meet the diverse needs of online customers (HD or C\&C, fast or cheap delivery). Looking at the picking location, $50.0 \%$ of the companies uses both the $\mathrm{CW}$ and the stores to fulfil online orders. The picking location typically changes according to the delivery mode selected by the customer. Online orders are processed in-store when involve C\&C, as well as when the $\mathrm{CW}$ does not carry the complete assortment. For HD, companies traditionally use one or at most two depots to serve all the country (national delivery area in $50.0 \%$ of the retailers). The dominant transport service is LTL (44.4\%), with traditional or express couriers according to the item size. For small items, the most-effective solution is LTL express courier, while with larger items, retailers prefer LTL couriers. With low online sales, there is no justification for investments in automation and picking is normally manual (94.4\%). Since the piece is the picking unit for both the traditional and the online channels, picking typically turns out to be integrated $(66.7 \%)$, while the packaging is specifically designed for the online channel. In non-food retailing, where companies adopt multiple options as picking location, the dominant allocation option is dynamic (72.2\%). Finally, the dominant returns mode remains CEP returns (offered by $89.0 \%$ of the companies belonging to this group). Nevertheless, it is worth noting that many retailers, with a view of 
integrating online and traditional channels, are introducing in-store returns as alternative option $(44.5 \%)$.

\section{XXXXXXXXXXXXXXXXXXXXXXXXXXXXXXXXXXXXXXXXXXXXXXXXXXXXXXX}

Take in Figure 6

\section{XXXXXXXXXXXXXXXXXXXXXXXXXXXXXXXXXXXXXXXXXXXXXXXXXXXXXXX}

Looking at the results, we can confirm that each company has reached a certain OC maturity so far, that means a certain ability to integrate and coordinate operations among channels and, thus, a certain ability to provide customers a seamless shopping experience. In food manufacturing, online and traditional channels are still distinct from a logistics viewpoint, without the opportunity to provide customers with a seamless shopping experience among different channels. The first and, so far, the only attempt to integrate online and traditional flows concerns inventory management and picking activities at warehouse level. Food retailers are one step ahead, with companies characterised by midlevels of OC maturity. Here the store assumes a critical role in the e-fulfilment process - either as pickup point, picking location, or starting point for local distribution routes. A high OC maturity has been observed in non-food retailing, with a significant search for synergy between the channels and the adoption of multiple configurations according to product characteristics and customer's requirements. This means introducing multiple inventory and picking locations and multiple transport services - that can be dedicated or shared between online and traditional channels - and selecting case by case the one that better fits customer's needs. In line with Hübner et al. (2016c) and Saghiri et al. (2017), such model is possible thanks to synchronised processes among channels at both organisation and IT systems level, that for instance allows having a dynamic order allocation.

\section{Conclusions}

Traditional manufacturing and retailing models are changing significantly with the arrival of the OC phenomenon. While research so far has mainly adopted a sales-based perspective without addressing logistics issues, this paper focused on the logistics challenges related to the development of an OC management strategy.

Based on the previous literature and three case studies, we proposed a classification framework for the key variables that companies have to consider when implementing their business logistics model in OC. We identified eleven logistics variables (delivery mode, velocity, time slot, slot price differentiation, picking location, delivery area, transport service, automation, integration, order 
allocation and returns mode), belonging to four strategic areas (delivery service, distribution setting, fulfilment strategy and returns management).

Applying the framework to a sample of 92 Italian companies revealed a picture in which the definition of the business logistics model is still ongoing, with each company having reached a certain OC maturity so far, that means a certain ability to coordinate operations among channels and, thus, a certain ability to provide customers a seamless shopping experience. The main enablers of an OC proposition seem to be channel integration and coexistence of multiple configurations, dynamically used according to product characteristics and customer requirements. Specifically, the cluster analysis has revealed four business logistics models, adopted in different business sectors and characterised by different OC maturity.

Results provide both practical and academic implications. From an academic perspective, the paper offers interesting insights into the underlying mechanisms of developing an OC management strategy from an operational point of view. First, this study extends the research on logistics design in OC by providing an overview of the key design elements and offering a broad empirical analysis. Although prior research has discussed some key strategic areas and variables for OC companies, introducing conceptual frameworks and performing exploratory interviews/case studies (Lang and Bressolles, 2013; Hübner et al., 2016b), an explanatory quantitative analysis has never been proposed. To address this knowledge gap, we provided a broad empirical investigation of the choices made by companies when setting the logistics variables to implement an OC strategy. We also investigated, using a cluster analysis, how the logistics variables combine and work together, identifying four business logistics models currently adopted by companies implementing an OC management strategy. Second, our results can be viewed as a first step towards understanding under what circumstances different business logistics models fit better. Some scholars suggested that there is not just one optimal business logistics model for every company, business sector and customer (Laseter et al., 2006; Hübner et al., 2016b). Coherently, we observed that not all the companies adopted the same business logistics model. Our results showed a statistically significant relationship between the company business sector and the business logistics model adopted. Furthermore, we highlighted that multiple configurations are sometimes adopted within the same business sector, or even within the same company according to their OC maturity, the product specific characteristics and the customer's specific requirements. Third, our results enrich the previous contributions (PwC, 2015; Hübner et al., 2016c) that started formalising the concept of OC maturity by identifying the coexistence of multiple configurations as a key element to implement an OC management strategy in addition to channel integration.

From a practical perspective, several implications have emerged. First, the proposed framework can represent a guide for traditional companies willing to include the online sales into their businesses, 
as it provides an overview of the key elements (logistics variables and related options) to be taken into account, summarises the choices made by companies operating in different business sectors, and investigates how different elements interact with one another in building a strategy. Also, for those companies already operating in an OC environment, this type of sectoral analysis can provide a basis for benchmarking. Second, the results highlight the existence of various business logistics models characterised by different OC maturity. More mature companies revealed interesting examples of synergies between channels, concerning both picking and transport activities. For instance, looking at the transport service, some retailers use the daily replenishment of stores to ship also pickup points products, as well as combine traditional and online orders with HD to increase the number of orders per drop. Third, overall results show the absence of a "one-fits-all" business logistics model, and the adoption, in more mature contexts (non-food retailing), of multiple configurations. The ability of combining multiple configurations, as well as the flexibility in changing the configuration adopted over time seem to be key issues to enable an OC proposition.

Although interesting results and findings came out of this study, limitations do exist. The main limitation is related to the sample selection. Our results cannot be generalised to smaller-sized companies nor other countries unless further investigation is performed. Nevertheless, the study presented is a first attempt to explore a research area that is still under-researched and to address a recent phenomenon such as OC.

Based on survey results, multiple potential areas for further research are identified: for instance, the investigation of how to develop a mixed transport service and the understanding of how to implement a dynamic allocation policy. Additionally, further research is needed to evaluate how contextual elements can affect the business logistics model adopted by companies and, more generally, the success of an OC strategy. Specifically, the following contextual elements should be analysed in greater detail: e-commerce importance (e.g. volumes), not only for the company, but also at country level; goods (e.g. value density); and marketing strategy (product range, customisation, transport charges). Finally, the logistics perspective presented in this paper could be valuably included and discussed within some more generalist OC frameworks available - such as the one by Saghiri et al. (2017) - thus to provide a more holistic and synergetic approach.

\section{References}

Agatz, N., Campbell, A., Fleischmann, M. and Savelsbergh, M. (2011), "Time slot management in attended home delivery”, Transportation Science, Vol. 45 No. 3, pp. 435-449.

Agatz, N., Fleischmann, M. and Van Nunen, J. A. (2008), "E-fulfillment and multi-channel distribution-A review", European Journal of Operational Research, Vol. 187 No. 2, pp. 339356. 
Alptekinoğlu, A. and Tang, C. S. (2005), "A model for analyzing multi-channel distribution systems", European Journal of Operational Research, Vol. 163 No. 3, pp. 802-82.

Beck, N. and Rygl, D. (2015), "Categorization of multiple channel retailing in Multi-, Cross-, and Omni-Channel Retailing for retailers and retailing”, Journal of Retailing and Consumer Services, Vol. 27, pp. 170-178.

Bell, D.R., Gallino, S. and Moreno, A. (2014), "How to win in an omni-channel world", MIT Sloan Management Review, Vol. 56 No. 1, pp. 45-55.

Bendoly, E., Blocher, J. D., Bretthauer, K. M., Krishnan, S. and Venkataramanan, M. A (2005), "Online/Instore Integration and Customer Retention", Journal of Service Research, Vol. 7 No. 4, pp. 313-27.

Bendoly, E., Blocher, D., Bretthauer, K. M. and Venkataramanan, M. A. (2007), "Service and cost benefits through clicks-and-mortar integration: Implications for the centralization/decentralization debate", European Journal of Operational Research, Vol. 180 No. 1, pp. 426-442.

Bernon, M., Cullen, J. and Gorst, J. (2016), "Online retail returns management: Integration within an omni-channel distribution context", International Journal of Physical Distribution \& Logistics Management, Vol. 46 No. 6/7, pp. 584-605.

Bhatnagar, A. and Syam, S. S. (2014), "Allocating a hybrid retailer's assortment across retail stores: Bricks-and-mortar vs online”, Journal of Business Research, Vol. 67 No. 6, pp. 1293-1302.

Bretthauer, K. M., Mahar, S. and Venakataramanan, M. A. (2010), "Inventory and distribution strategies for retail/e-tail organizations", Computers \& Industrial Engineering, Vol. 58 No. 1, pp. 119-132.

Brynjolfsson, E., Hu, Y. J. and Rahman, M. S. (2013), "Competing in the Age of Omnichannel Retailing”, MIT Sloan Management Review, Vol. 54 No. 4, pp. 23-9.

Cao, L. and Li, L. (2015), "The Impact of Cross-Channel Integration on retailers Sales Growth", Journal of Retailing, Vol. 9 No. 2, pp. 198-216.

Chiang, W. Y. K. and Monahan, G. E. (2005), "Managing inventories in a two-echelon dual-channel supply chain”, European Journal of Operational Research, Vol. 162 No. 2, pp. 325-341.

De Koster, R. B. M. (2003), "Distribution strategies for online retailers", IEEE Transactions on Engineering Management, Vol. 50 No. 4, pp. 448-457.

Dubois, A. and Gadde, L.E. (2002), "Systematic combining: an abductive approach to case research", Journal of Business Research, Vol. 55 No. 7, pp. 553-560.

Fernie, J. and Grant, D. B. (2008), "On-shelf availability: the case of a UK grocery retailer", The International Journal of Logistics Management, Vol. 19 No. 3, pp. 293-308.

Fernie, J. and Sparks, L. (2014), Logistics and retail management: emerging issues and new challenges in the retail supply chain, Kogan Page, London.

Fink, A. (2003), The survey handbook, Sage, Thousand Oaks, CA. 
Gallino, S. and Moreno, A. (2014), "Integration of online and offline channels in retail: The impact of sharing reliable inventory availability information", Management Science, Vol. 60 No. 6, pp. 1434-1451.

Herhausen, D., Binder, J., Schoegel, M. and Herrmann, A. (2015), "Integrating Bricks with Clicks: Retailer-Level and Channel-Level Outcomes of Online-offline Channel Integration", Journal of Retailing, Vol. 91 No. 2, pp. 309-325.

Hübner, A., Holzapfel, A. and Kuhn, H. (2015), "Operations management in multi-channel retailing: an exploratory study", Operational Management Research, Vol. 8 No. 3, pp. 84-100.

Hübner, A., Holzapfel, A. and Kuhn, H. (2016a), "Distribution systems in omni-channel retailing", Business Research, Vol. 9 No. 2, pp. 255-296.

Hübner, A., Kuhn, H. and Wollenburg, J. (2016b), "Last mile fulfilment and distribution in omnichannel grocery retailing: A strategic planning framework", International Journal of Retail and Distribution Management, Vol. 44 No. 3, pp. 228-247.

Hübner, A., Wollenburg, J. and Holzapfel, A. (2016c), "Retail logistics in the transition from multichannel to omni-channel" International Journal of Physical Distribution \& Logistics Management, Vol. 46 No. 6/7, pp. 562-583.

IBM (2015), “IBM Omnichannel Capability Index (OmCI) Survey 2015”, available at: http://www01.ibm.com/software/it/pdf/6855_EU_OmCi_2015_flyer_v3.pdf.

Ishfaq, R., Defee, C., Gibson, B. J. and Raja, U. (2016), "Realignment of the physical distribution process in omni-channel fulfilment", International Journal of Physical Distribution and Logistics Management, Vol. 46 No. 6/7, pp. 543 - 561.

Jansen, H. (2010), "The logic of qualitative survey research and its position in the field of social research methods", In Forum Qualitative Sozialforschung/Forum: Qualitative Social Research, Vol. 11 No. 2.

Kämäräinen, V. and Punakivi, M. (2002), "Developing cost-effective operations for the e-grocery supply chain”, International Journal of Logistics, Vol. 5 No. 3, pp. 285-298.

Klein, R., Neugebauer, M., Ratkovitch, D. and Steinhardt, C. (2017), "Differentiated time slot pricing under routing considerations in attended home delivery", Transportation Science.

Kozinets, R. V., Sherry, J. F., DeBerry-Spence, B., Duhachek, A., Nuttavuthisit, K. and Storm, D. (2002), "Themed flagship brand stores in the new millennium: theory, practice, prospects", Journal of Retailing, Vol. 78 No. 1, pp. 17-29.

Landers, T. L., Cole, M. H., Walker, B. and Kirk, R. W. (2000), "The virtual warehousing concept" Transportation Research Part E: Logistics and Transportation Review, Vol. 36 No. 2, pp. 115126.

Lang, G. and Bressolles, G. (2013), "Economic performance and customer expectation in efulfillment systems: A multi-channel retailer perspective", Supply Chain Forum: An International Journal, Vol. 14 No. 1, pp. 16-26.

Laseter, T. M., Rabinovich, E. and Huang, A. (2006), “The Hidden Costs of Clicks", Strategy and Business, Vol. 42, pp. 26-30. 
Liu, K., Zhou, Y. and Zhang, Z. (2010), "Capacitated location model with online demand pooling in a multi-channel supply chain”, European Journal of Operational Research, Vol. 207 No. 1, pp. 218-231.

Mahar, S., Bretthauer, K. M. and Venkataramanan, M. A. (2009), "The value of virtual pooling in dual sales channel supply chains”, European Journal of Operational Research, Vol. 192 No. 2, pp. 561-575.

Mahar, S., Salzarulo, P. A. and Wright, P. D. (2012), "Using online pickup site inclusion policies to manage demand in retail/e-tail organizations", Computers and Operations Research, Vol. 39 No. 5, pp. 991-999.

Mahar, S. and Wright, P. D. (2009), "The value of postponing online fulfillment decisions in multichannel retail/e-tail organizations", Computers \& Operations Research, Vol. 36 No. 11, pp. 3061-3072.

Marchet, G., Melacini, M., Perotti, S., Sassi, C. and Tappia, E. (2017), "Value creation models in the 3PL industry: what 3PL providers do to cope with shipper requirements", International Journal of Physical Distribution \& Logistics Management, Vol. 47 No. 6, pp. 472-494.

Marchet, G., Melacini, M., Perotti, S. and Tappia, E. (2013), "Development of a framework for the design of autonomous vehicle storage and retrieval systems", International Journal of Production Research, Vol. 51 No. 14, pp. 4365-4387.

Nilsson, E., Gärling, T., Marell, A. and Nordvall, A. C. (2015), "Importance ratings of grocery store attributes", International Journal of Retail \& Distribution Management, Vol. 43 No. 1, pp. 63 91.

Piotrowicz, W. and Cuthbertson, R. (2014), "Introduction to the special issue information technology in retail: toward omnichannel retailing", International Journal of Electronic Commerce, Vol. 18 No. 4, pp. 5-16.

Punakivi, M. and Saranen, J. (2001), "Identifying the success factors in e-grocery home delivery", International Journal of Retail \& Distribution Management, Vol. 29 No. 4, pp. 156-163.

Punakivi, M., Yrjölä, H. and Holmström, J. (2001), "Solving the last mile issue: reception box or delivery box?", International Journal of Physical Distribution \& Logistics Management, Vol. 31 No. 6, pp. 427-439.

PwC (2015), "The 2015 Global omni-channel retail index", available at: https://www.strategyand.pwc.com/media/file/2015-global-omnichannel-retail-index.pdf.

Saghiri, S., Wilding, R., Mena, C. and Bourlakis, M. (2017), “Toward a three-dimensional framework for omni-channel”, Journal of Business Research, Vol. 77, pp. 53-67.

Schneider, F. and Klabjan, D. (2013), "Inventory control in multi-channel retail", European Journal of Operational Research, Vol. 227 No. 1, pp. 101-111.

Surchi, M. (2011), "The temporary store: a new marketing tool for fashion brands", Journal of Fashion Marketing and Management: An International Journal, Vol. 15 No. 2, pp. 257-270.

Swaminathan, J. M. and Tayur, S. R. (2003), "Models for supply chains in e-business", Management Science, Vol. 49 No. 10, pp. 1387-1406. 
Tappia, E., Roy, S., De Koster, R. and Melacini, M. (2017), "Modeling, Analysis, and Design Insights for Shuttle-Based Compact Storage Systems”, Transportation Science, Vol. 51 No. 1, pp. 269295.

Verhoef, P. C., Kannan, P. K. and Inman, J. J. (2015), "From multi-channel retailing to omni-channel retailing: introduction to the special issue on multi-channel retailing", Journal of Retailing, Vol. 91 No. 2, pp. 174-181.

Wang, X., Zhan, L., Ruan, J. and Zhang, J. (2014), "How to Choose "Last Mile” Delivery Modes for E-Fulfillment", Mathematical Problems in Engineering, 2014.

Widodo, E., Takahashi, K., Morikawa, K., Pujawan, I. N. and Santosa, B. (2011), "Managing sales return in dual sales channel: its product substitution and return channel analysis", International Journal of Industrial and Systems Engineering, Vol. 9 No. 2, pp. 121-149.

Xie, W., Jiang, Z., Zhao, Y. and Hong, J. (2014), "Capacity planning and allocation with multichannel distribution", International Journal of Production Economics, Vol. 147 No. 1, pp. 108116. 


\begin{tabular}{l|c|c|c|cc}
\hline $\begin{array}{c}\text { Annual revenues } \\
{[\mathbf{m} \mathbf{l n} \boldsymbol{\epsilon}]}\end{array}$ & $\begin{array}{c}\text { Food Manufacturer } \\
\text { No. }\end{array}$ & $\begin{array}{c}\text { Food Retailer } \\
\text { No. }\end{array}$ & $\begin{array}{c}\text { Non-food Retailer } \\
\text { No. }\end{array}$ & \multicolumn{2}{|c}{ Total } \\
No. & Percentage \\
\hline$<100$ & 30 & 1 & 6 & 37 & $40 \%$ \\
$100-500$ & 23 & 4 & 9 & 36 & $39 \%$ \\
$500-1,000$ & 2 & 2 & 1 & 5 & $6 \%$ \\
$>1,000$ & 2 & 6 & 6 & 14 & $15 \%$ \\
\hline
\end{tabular}

Table 1 - Description of the sample: company turnover. Note that the percentages are referred to the entire sample of 92 companies.

\begin{tabular}{l|c|c|c|cc}
\hline Company size & $\begin{array}{c}\text { Food Manufacturer } \\
\text { No. }\end{array}$ & $\begin{array}{c}\text { Food Retailer } \\
\text { No. }\end{array}$ & $\begin{array}{c}\text { Non-food Retailer } \\
\text { No. }\end{array}$ & \multicolumn{2}{|c}{ Total } \\
\hline Small-size & 16 & 0 & 2 & 18 & Percentage \\
Medium-size & 24 & 2 & 2 & $28 \%$ \\
Large-size & 17 & 11 & 18 & 46 & $50 \%$ \\
\hline
\end{tabular}

Table 2 - Description of the sample: company size expressed in terms of number of employees (we refer to the definition in the 2003/361/EC Recommendation as for small-, $\leq 50$ employees, medium-, $50<$ employees $\leq 250$, and large-sized companies, $>250$ employees). Note that the percentages are referred to the entire sample of 92 companies. 


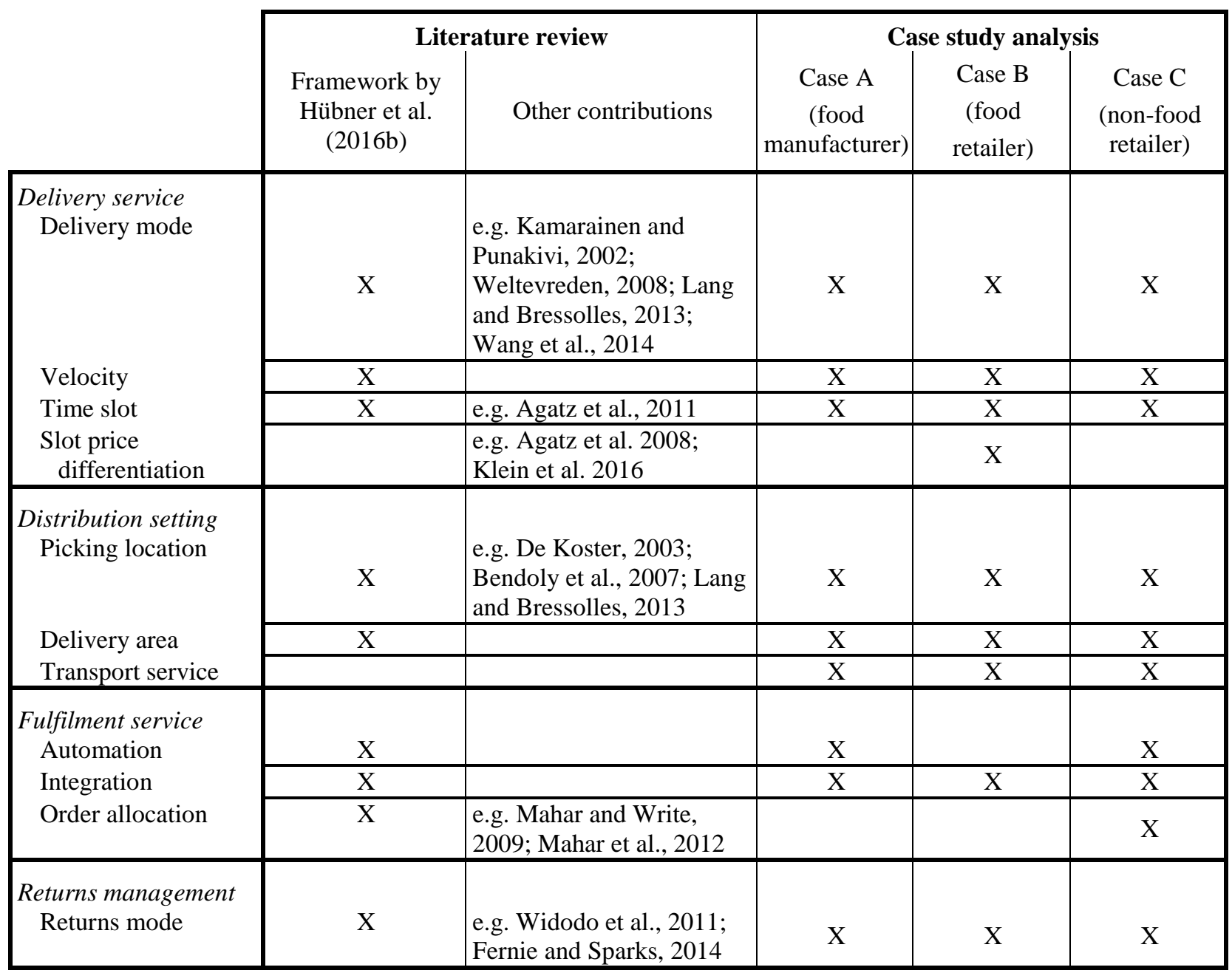

Table 3 - Framework definition: contribution from literature review and explorative case study analysis. 


\begin{tabular}{|c|c|c|c|c|c|c|}
\hline & \multicolumn{2}{|c|}{ Food Manufacturer } & \multicolumn{2}{|c|}{ Food Retailer } & \multicolumn{2}{|c|}{ Non-food Retailer } \\
\hline & No. & Percentage & No. & Percentage & No. & Percentage \\
\hline $\begin{array}{l}\text { Delivery mode } \\
\text { Attended HD } \\
\text { Unattended HD } \\
\text { In-store C\&C } \\
\text { Attached C\&C } \\
\text { Solitary C\&C }\end{array}$ & $\begin{array}{c}57 \\
0 \\
2 \\
0 \\
3\end{array}$ & $\begin{array}{c}100 \% \\
0 \% \\
4 \% \\
0 \% \\
5 \%\end{array}$ & $\begin{array}{l}7 \\
0 \\
4 \\
5 \\
1\end{array}$ & $\begin{array}{c}54 \% \\
0 \% \\
31 \% \\
38 \% \\
8 \%\end{array}$ & $\begin{array}{c}19 \\
0 \\
13 \\
0 \\
3\end{array}$ & $\begin{array}{c}86 \% \\
0 \% \\
59 \% \\
0 \% \\
14 \%\end{array}$ \\
\hline $\begin{array}{l}\text { Velocity } \\
\text { Same day } \\
\text { Next day } \\
\text { Two or more days }\end{array}$ & $\begin{array}{c}1 \\
9 \\
52\end{array}$ & $\begin{array}{c}2 \% \\
16 \% \\
91 \%\end{array}$ & $\begin{array}{c}10 \\
3 \\
1\end{array}$ & $\begin{array}{c}77 \% \\
23 \% \\
8 \%\end{array}$ & $\begin{array}{c}9 \\
9 \\
20\end{array}$ & $\begin{array}{l}41 \% \\
41 \% \\
91 \%\end{array}$ \\
\hline $\begin{array}{l}\text { Time slot } \\
\text { Specific } \\
\text { Undefined }\end{array}$ & $\begin{array}{c}1 \\
57\end{array}$ & $\begin{array}{c}2 \% \\
100 \%\end{array}$ & $\begin{array}{c}13 \\
0\end{array}$ & $\begin{array}{c}100 \% \\
0 \%\end{array}$ & $\begin{array}{c}0 \\
22\end{array}$ & $\begin{array}{c}0 \% \\
100 \%\end{array}$ \\
\hline $\begin{array}{l}\text { Slot price differentiation } \\
\text { Yes } \\
\text { No }\end{array}$ & $\begin{array}{c}0 \\
57\end{array}$ & $\begin{array}{c}0 \% \\
100 \%\end{array}$ & $\begin{array}{c}0 \\
13\end{array}$ & $\begin{array}{c}0 \% \\
100 \%\end{array}$ & $\begin{array}{c}0 \\
22\end{array}$ & $\begin{array}{c}0 \% \\
100 \%\end{array}$ \\
\hline
\end{tabular}

Table 4 - Delivery service: adoption rates of the options identified in the classification framework (base: 92 companies). Note that for each logistics variable multiple options can be potentially adopted.

\begin{tabular}{|c|c|c|c|c|c|c|}
\hline & \multicolumn{2}{|c|}{ Food Manufacturer } & \multicolumn{2}{|c|}{ Food Retailer } & \multicolumn{2}{|c|}{ Non-food Retailer } \\
\hline & No. & Percentage & No. & Percentage & No. & Percentage \\
\hline \multicolumn{7}{|l|}{ Picking location } \\
\hline Central warehouse & 20 & $35 \%$ & 0 & $0 \%$ & 16 & $73 \%$ \\
\hline $\begin{array}{l}\text { Separate fulfilment } \\
\text { centre }\end{array}$ & 37 & $65 \%$ & 3 & $23 \%$ & 6 & $27 \%$ \\
\hline In-store & 0 & $0 \%$ & 11 & $85 \%$ & 10 & $45 \%$ \\
\hline \multicolumn{7}{|l|}{ Delivery area } \\
\hline Local & 1 & $2 \%$ & 13 & $100 \%$ & 10 & $45 \%$ \\
\hline Regional & 0 & $0 \%$ & 0 & $0 \%$ & 3 & $14 \%$ \\
\hline National & 56 & $98 \%$ & 0 & $0 \%$ & 16 & $73 \%$ \\
\hline \multicolumn{7}{|l|}{ Transportation service } \\
\hline Milk run & 0 & $0 \%$ & 7 & $54 \%$ & 3 & $14 \%$ \\
\hline LTL - express courier & 20 & $35 \%$ & 0 & $0 \%$ & 8 & $36 \%$ \\
\hline LTL - courier & 41 & $72 \%$ & 0 & $0 \%$ & 12 & $55 \%$ \\
\hline $\begin{array}{l}\text { FTL + local } \\
\text { distribution }\end{array}$ & 1 & $2 \%$ & 0 & $0 \%$ & 4 & $18 \%$ \\
\hline
\end{tabular}

Table 5 - Distribution setting: adoption rates of the options identified in the classification framework (base: 92 companies). Note that for each logistics variable multiple options can be potentially adopted. 


\begin{tabular}{|c|c|c|c|c|c|c|}
\hline & \multicolumn{2}{|c|}{ Food Manufacturer } & \multicolumn{2}{|c|}{ Food Retailer } & \multicolumn{2}{|c|}{ Non-food Retailer } \\
\hline & No. & Percentage & No. & Percentage & No. & Percentage \\
\hline \multicolumn{7}{|l|}{ Automation } \\
\hline Manual & 56 & $98 \%$ & 13 & $100 \%$ & 21 & $95 \%$ \\
\hline Semi-automated & 1 & $2 \%$ & 0 & $0 \%$ & 0 & $0 \%$ \\
\hline Fully automated & 0 & $0 \%$ & 0 & $0 \%$ & 1 & $5 \%$ \\
\hline \multicolumn{7}{|l|}{ Integration } \\
\hline Separated & 37 & $65 \%$ & 5 & $38 \%$ & 9 & $41 \%$ \\
\hline Integrated & 20 & $35 \%$ & 8 & $62 \%$ & 17 & $77 \%$ \\
\hline $\begin{array}{l}\text { Capacity-optimised \& } \\
\text { Integrated }\end{array}$ & 0 & $0 \%$ & 0 & $0 \%$ & 0 & $0 \%$ \\
\hline \multicolumn{7}{|l|}{ Order Allocation } \\
\hline Static & 57 & $100 \%$ & 13 & $100 \%$ & 9 & $41 \%$ \\
\hline Dynamic & 0 & $0 \%$ & 0 & $0 \%$ & 13 & $59 \%$ \\
\hline
\end{tabular}

Table 6 - Fulfilment strategy: adoption rates of the options identified in the classification framework (base: 92 companies). Note that for each logistics variable multiple options can be potentially adopted.

\begin{tabular}{l|cc|cc|cc}
\hline & \multicolumn{2}{|c|}{ Food Manufacturer } & \multicolumn{2}{c|}{ Food Retailer } & \multicolumn{2}{c}{ Non-food Retailer } \\
& No. & Percentage & No. & Percentage & No. & Percentage \\
\hline Returns mode & & & & & & \\
No returns & 0 & $0 \%$ & 13 & $100 \%$ & 0 & $0 \%$ \\
CEP returns & 57 & $100 \%$ & 0 & $0 \%$ & 20 & $91 \%$ \\
In-store returns & 0 & $0 \%$ & 0 & $0 \%$ & 11 & $50 \%$ \\
\hline
\end{tabular}

Table 7 - Returns management: adoption rates of the options identified in the classification framework (base: 92 companies). Note that for each logistics variable multiple options can be potentially adopted.

\begin{tabular}{l|cc|cc|cc}
\hline & \multicolumn{2}{|c|}{ Food Manufacturer } & \multicolumn{2}{c|}{ Food Retailer } & \multicolumn{2}{c}{ Non-food Retailer } \\
& No. & Percentage & No. & Percentage & No. & Percentage \\
\hline Cluster 1 & 37 & $92.5 \%$ & 0 & $0 \%$ & 3 & $7.5 \%$ \\
Cluster 2 & 20 & $95 \%$ & 0 & $0 \%$ & 1 & $5 \%$ \\
Cluster 3 & 0 & $0 \%$ & 13 & $100 \%$ & 0 & $0 \%$ \\
Cluster 4 & 0 & $0 \%$ & 0 & $0 \%$ & 18 & $100 \%$ \\
\hline
\end{tabular}

Pearson Chi-Square: 162.4

Significant at $p<0.001$

Table 8 - Cluster analysis results: business sector distribution of the identified clusters. 


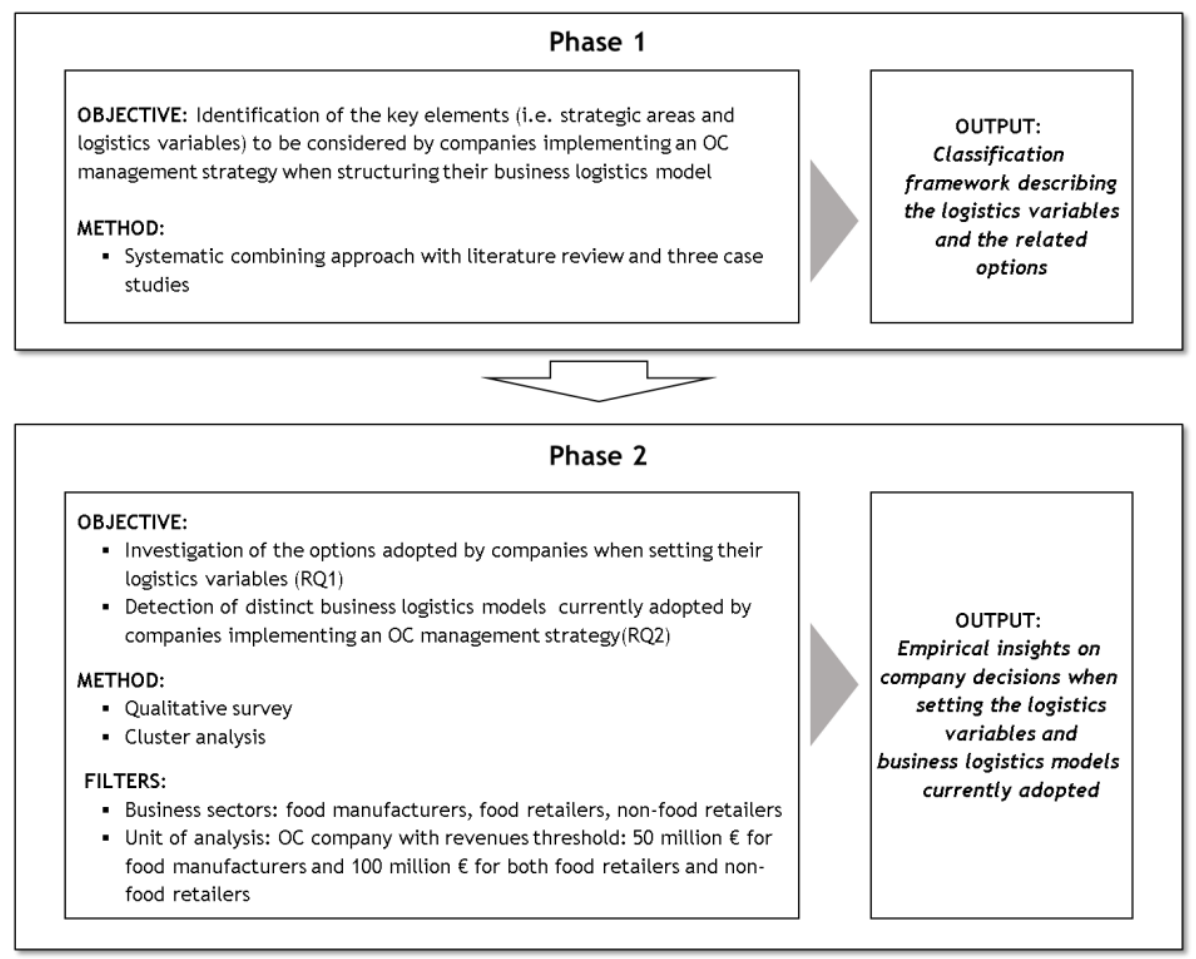

Figure 1 - Research methodology.

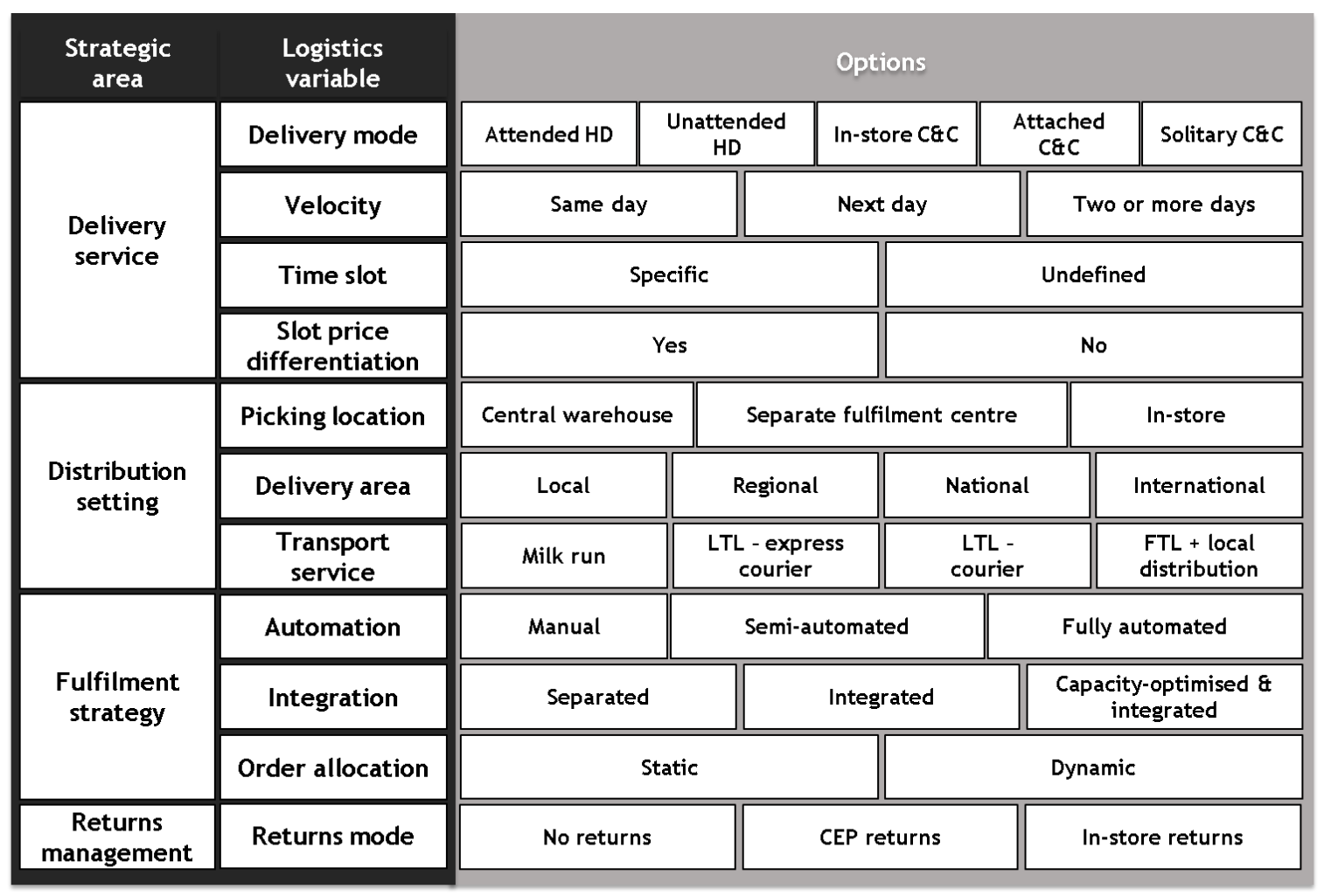

Note: $\mathrm{HD}=$ Home Delivery; $\mathrm{C} \& \mathrm{C}=$ Click and Collect; LTL = Less than Truck Load; FTL = Full than Truck Load; CEP = Courier, Express and Parcel.

Figure 2-Research framework. 


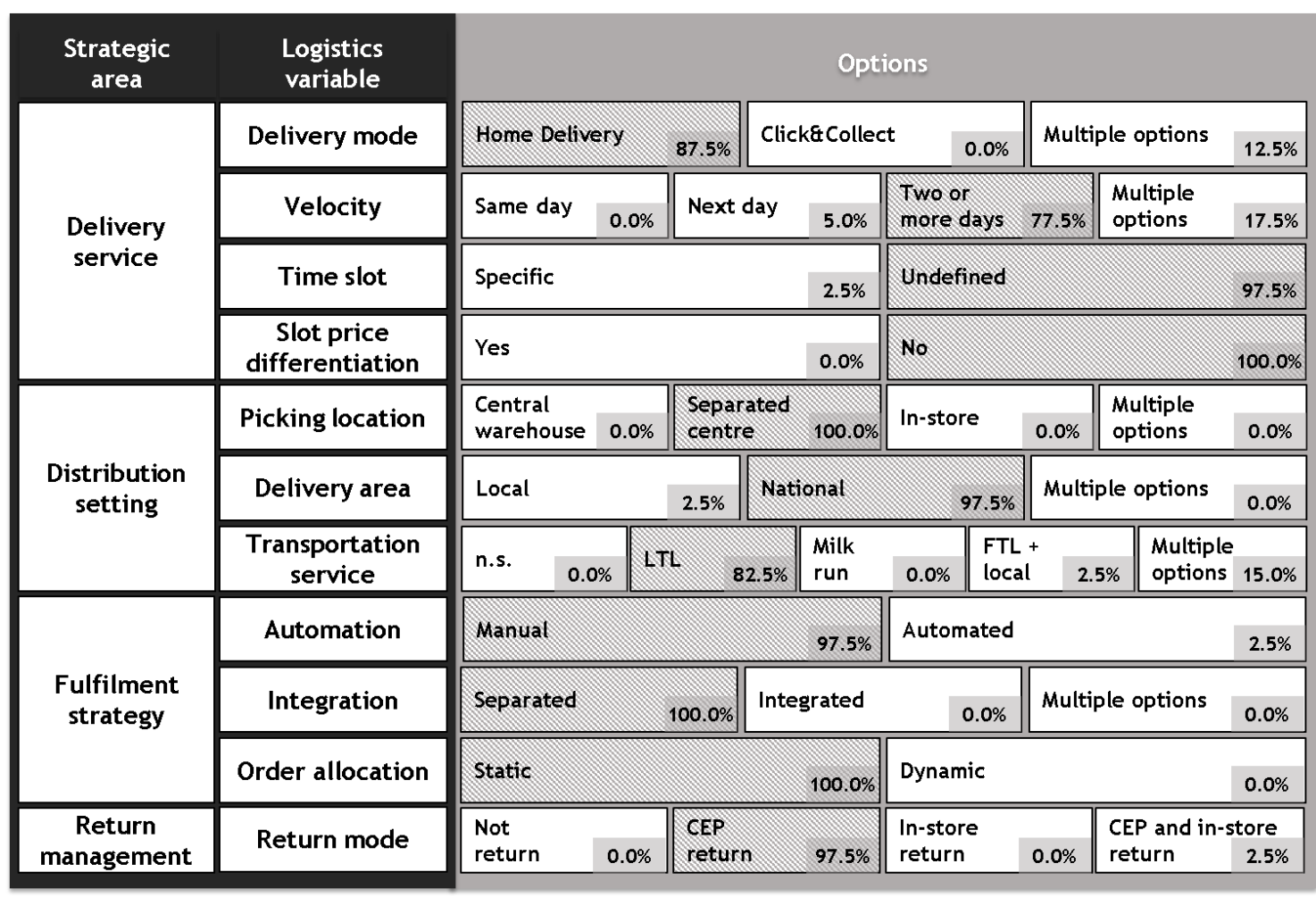

Note: n.s. = Not Significant (i.e. in case of C\&C as delivery mode)

Figure 3 - Cluster analysis results: Separated model characteristics.

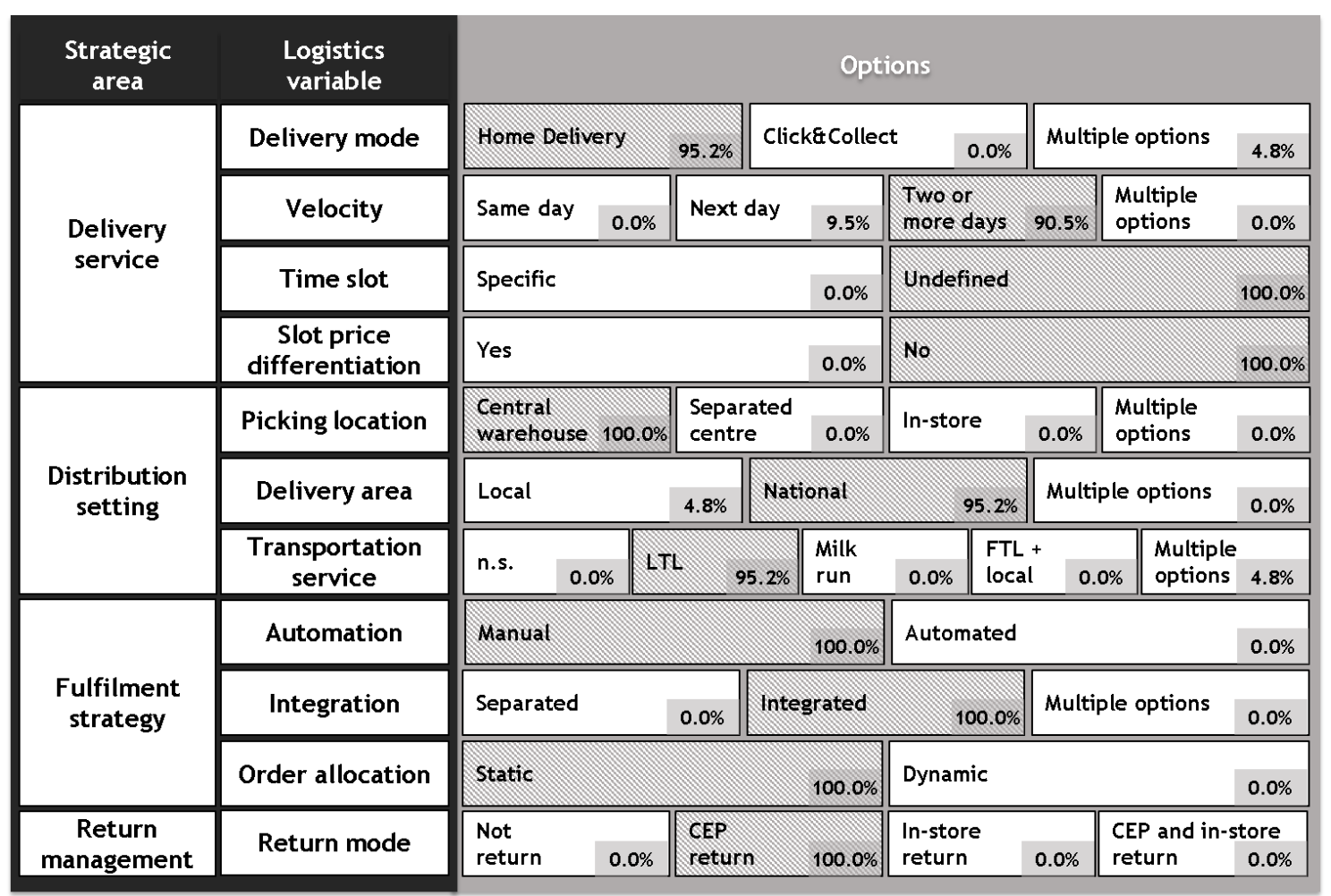

Note: n.s. = Not Significant (i.e. in case of $\mathrm{CaC}$ as delivery mode)

Figure 4 - Cluster analysis results: Integrated warehouse model characteristics. 


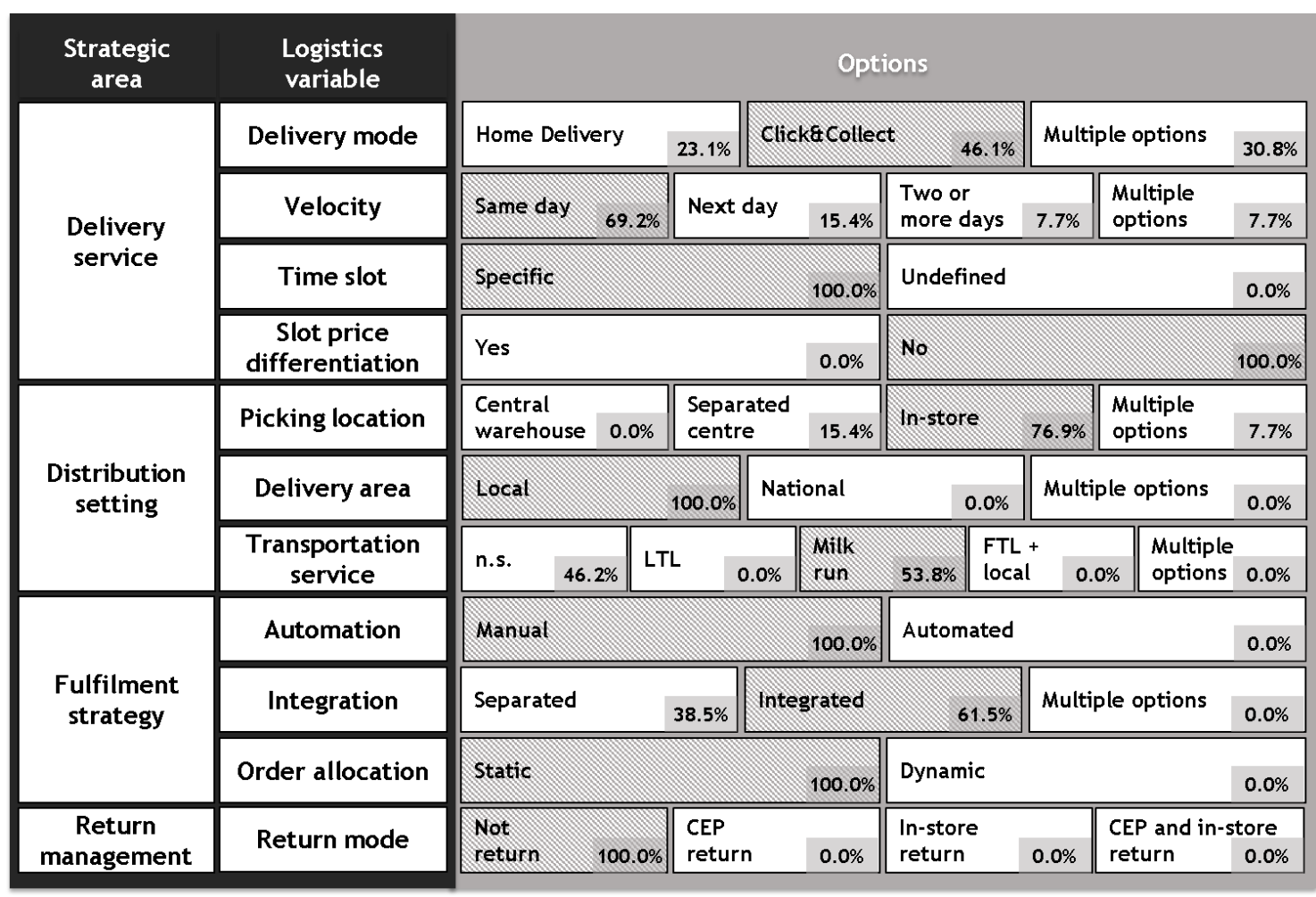

Note: n.s. = Not Significant (i.e. in case of C\&C as delivery mode)

Figure 5 - Cluster analysis results: Store-based model characteristics.

\begin{tabular}{|c|c|c|c|c|c|c|c|c|c|c|c|}
\hline $\begin{array}{l}\text { Strategic } \\
\text { area }\end{array}$ & $\begin{array}{l}\text { Logistics } \\
\text { variable }\end{array}$ & \multicolumn{10}{|c|}{ Options } \\
\hline \multirow{4}{*}{$\begin{array}{l}\text { Delivery } \\
\text { service }\end{array}$} & Delivery mode & \multicolumn{2}{|l|}{ Home Delivery } & $27.8 \%$ & \multicolumn{2}{|c|}{ Click\&Collect } & \multicolumn{2}{|c|}{$16.7 \%$} & \multicolumn{2}{|c|}{ Multiple options } & $55.5 \%$ \\
\hline & Velocity & Same day 0 & $0.0 \%$ & \multicolumn{2}{|c|}{ Next day } & $0.0 \%$ & \multicolumn{2}{|c|}{$\begin{array}{l}\text { Two or } \\
\text { more days }\end{array}$} & $33.3 \%$ & $\begin{array}{l}\text { Multiple: } \\
\text { options }\end{array}$ & $66.7 \%$ \\
\hline & Time slot & \multicolumn{4}{|l|}{ Specific } & $0.0 \%$ & \multicolumn{4}{|c|}{ Undefined } & $100.0 \%$ \\
\hline & $\begin{array}{c}\text { Slot price } \\
\text { differentiation }\end{array}$ & \multicolumn{4}{|l|}{ Yes } & $0.0 \%$ & \multicolumn{4}{|l|}{ No } & $100.0 \%$ \\
\hline \multirow{3}{*}{$\begin{array}{l}\text { Distribution } \\
\text { setting }\end{array}$} & Picking location & $\begin{array}{l}\text { Central } \\
\text { warehouse } 44\end{array}$ & $44.4 \%$ & $\begin{array}{l}\text { Separa } \\
\text { centre }\end{array}$ & rated & $0.0 \%$ & In-stor & & $5.6 \%$ & $\begin{array}{l}\text { Multiple } \\
\text { options }\end{array}$ & $50.0 \%$ \\
\hline & Delivery area & \multicolumn{2}{|l|}{ Local } & $27.8 \%$ & \multicolumn{2}{|c|}{ National } & & $50.0 \%$ & \multicolumn{2}{|c|}{ Multiple options } & $22.2 \%$ \\
\hline & $\begin{array}{c}\text { Transportation } \\
\text { service }\end{array}$ & $16.7 \%$ & LTL & L & $44.4 \%$ & $\begin{array}{l}\text { Milk } \\
\text { run }\end{array}$ & $5.6 \%$ & $\begin{array}{l}\mathrm{FTL} \\
\text { local }\end{array}$ & & $\begin{array}{l}\text { Multiple } \\
\text { options }\end{array}$ & $33.3 \%$ \\
\hline \multirow{3}{*}{$\begin{array}{l}\text { Fulfilment } \\
\text { strategy }\end{array}$} & Automation & \multicolumn{4}{|l|}{ Manual } & $94.4 \%$ & \multicolumn{4}{|c|}{ Automated } & $5.6 \%$ \\
\hline & Integration & \multicolumn{2}{|l|}{ Separated } & $11.1 \%$ & \multicolumn{2}{|c|}{ Integrated } & & $6.7 \%$ & \multicolumn{2}{|c|}{ Multiple options } & $22.2 \%$ \\
\hline & Order allocation & \multicolumn{4}{|l|}{ Static } & $27.8 \%$ & \multicolumn{4}{|c|}{ Dynamic } & $72.2 \%$ \\
\hline $\begin{array}{c}\text { Return } \\
\text { management }\end{array}$ & Return mode & $\begin{array}{l}\text { Not } \\
\text { return }\end{array}$ & $0.0 \%$ & \multicolumn{2}{|c|}{$\begin{array}{l}\text { CEP } \\
\text { return }\end{array}$} & $44.5 \%$ & \multicolumn{2}{|c|}{$\begin{array}{l}\text { In-store } \\
\text { return }\end{array}$} & $11.0 \%$ & \multicolumn{2}{|c|}{$\begin{array}{l}\text { CEP and in-store } \\
\text { return } 44.5 \%\end{array}$} \\
\hline
\end{tabular}

Note: n.s. = Not Significant (i.e. in case of $\mathrm{CaC}$ as delivery mode)

Figure 6-Cluster analysis results: Multiple-configuration model characteristics. 